\title{
Circular Economy and Strategic Management of the Construction Company
}

\author{
Aneta Marichova
}

\begin{abstract}
One of the EU's main priorities is sustainable development, which imposes the leading concept of a circular economy - an alternative economic model of the traditional linear economy. This poses new challenges to the company and managers and requires significant changes in strategic management, aimed at building competitive advantages by creating, offering and realizing additional economic, social and environmental value for the client, stakeholders and society as a whole. From this point of view, the research aims to: 1) Develop a model of strategic management relationship between the circular development and the building of competitive company advantages, 2) Empirical study of the indicated connections and dependencies in the model and the influence on the process of building competitive advantages in companies operating on the construction market.
\end{abstract}

Keywords - circular economy, competitive advantages, construction company, strategic management

\section{INTRODUCTION}

The trend towards sustainable development also imposes the concept of a circular economy, which is becoming one of the main priorities of the EU. The concept of a circular economy is an alternative economic model, calling into question the traditional linear economy (the "Take - Make - Dispose/Waste" model), which focuses on high productivity and low production costs, relying on the abundance of raw materials at a relatively low price (Fig.1). The typical linear model includes several stages - extraction of raw materials, production, consumption and generation of waste from used products at the end of their life cycle. Once this product is no longer needed, it is discarded. For these reasons, only one third of the materials used in the economy reach the end user, and only $1-2 \%$ of the products that are bought and consumed are preserved. Everything else is classified as waste, which is discarded and only a small part is recycled.

\section{RESOURCE $\rightarrow$ PRODUCTION $\rightarrow$ DISTRIBUTION $\rightarrow$ CONSUMPTION $\rightarrow$ WASTE}

Fig. 1. Linear model of economy- "Take - Make - Dispose (Waste)"

The circular economy aims to end this practice. In December 2015, the European Commission adopted an ambitious new circular economy package, which includes actions to contribute to the "closing of the chain" of products [1]. In 2019, the EC adopts the Green 
Deal [2], which includes a package of actions aimed at tackling climate and environmental challenges that are closely linked and with the concept of sustainable development and the circular economy. The Circular Economy Action Plan, adopted by the Commission (March 2020) aims to accelerate transformational change by streamlining the regulatory framework to achieve a cleaner, climate-neutral, resource-efficient and competitive economy [3]. These documents propose a rethinking of EU policy by introducing changes in the stages of the product life cycle: design (idea), production, consumption, waste management and reuse of secondary materials. It is important to clarify that the circular economy is part of the general concept - a green economy, which means an efficient and socially just economy, providing growth through solutions and investments based on nature.

Interest in the circular economy is growing for various reasons. As more important than them in the first place are the environmental factors - the increasing scarcity of resources (especially of strategic resources such as rare earth elements) and the negative environmental impact of traditional production and consumption. The main economic reasons are the volatile prices of resources and products and the potential for economic benefits (worth billions of euros) from the introduction of the concept of a circular economy in new markets.

The circular economy strives for low environmental impact by limiting the amount of waste and overuse of resources, turning products after their use into resources for other industries, through reuse, secondary production, recycling, waste reduction and other practices [4]. This comprehensive definition highlights several aspects of the circular economy. On the one hand, there is a specific emphasis on the management of materials and resources. On the other hand, such an economic model requires the transformation of the economy and industrial processes [5]. Such a transformation should start from the design stage, rather than focusing on optimizing only one component of the system.

The circular economy is a development strategy that includes economic growth without increasing resource consumption, profound transformation of production chains and consumer habits, and redesign of industrial systems at the system level [6]. This approach profoundly transforms the function and role of resources: waste can become a valuable contribution to another process, while products can be repaired, reused or upgraded instead of disposed of [7]. Therefore, the circular economy aims to ensure economic growth and reduce the negative impact on the environment, while limiting the use of resources and reducing the amount of waste.

In short, the concept of a circular economy imposes a circular model that includes all stages of the product life cycle: Raw Materials, Resources $\rightarrow$ Product Design $\rightarrow$ Production $\rightarrow$ Distribution $\rightarrow$ Consumption, Use, Reuse, Repair $\rightarrow$ Collection $\rightarrow$ Waste Management $\rightarrow$ Recycling $\rightarrow$ Creation of New Raw Materials and Resources for Other Productions (Fig. 2). The aim is to turn the products after their use into resources for other productions, through re-use, secondary production, recycling, waste reduction and other practices or closing the cycle.

In realizing the idea of a circular economy, the construction market occupies a special place and is defined as one of the priority areas facing specific challenges, seeking an answer to the question: how long can nature and people withstand the environmental burden of construction and the development of new land for construction? It is an indisputable fact that construction is an activity with high resource intensity, related to the use of the scarcest resource - land, as well as a large amount of construction materials, energy and water and has a large share in environmental pollution. The construction sector itself accounts for $30-40 \%$ of world energy consumption, and over $70 \%$ of environmentally harmful emissions are due to electricity consumption during the operation of buildings. 


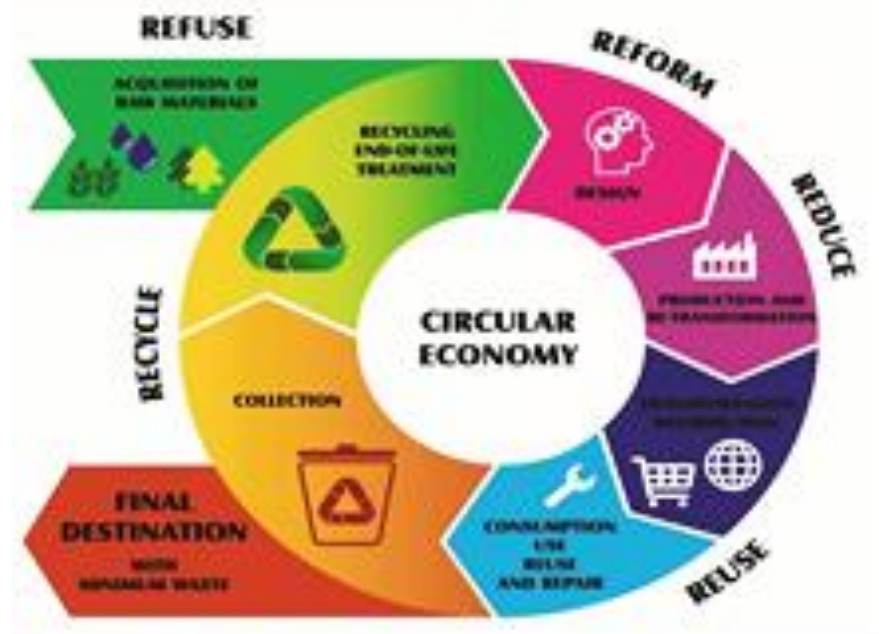

Fig. 2. The circular economy - Conceptual diagram (Source: European Commission - 2014)

The volume of waste from construction and demolition of buildings is one of the largest among the various types of waste in Europe. Valuable materials are not always identified and collected. Many of them can be recycled or reused, but the frequency of reuse and recycling varies considerably across the EU and is generally still insufficient. All these data show that the development and application of the principles of circular economy in construction (which can also be defined as the development of circular construction) can be a strong factor in reducing the amount of natural resources used, environmental pollution, increasing efficiency and market growth. However, this can be a fact only in economic development, in which market share and profits are not the main indicator of business success and the principles of environmental and social justice are not only a supplement to the main activities of the company. In other words, managers must make the concept of circular development a central part of their activities, which requires a significant change in strategic management - strategic behavior, strategic decisions and actions aimed at developing a strategy, which allows the creation, supply and realization of additional economic, social and environmental value for the client, stakeholders and society as a whole and which in practice means building competitive advantages in market dynamics.

From this point of view, the research aims to: 1) Develop a model of strategic management - relationship between the circular development and the building of competitive company advantages, 2) Empirical study of the indicated connections and dependencies in the model and the influence on the process of building competitive advantages in companies operating on the construction market.

\section{THEORETICAL FRAMEWORK OF THE STUDY}

The orientation of each company towards the application of the principles of circular development in its activity requires a fundamental rethinking of its organization and management: a new philosophy of product design, managing the entire product life cycle, building an effective integrated vertical management system (including recycled materials, reconstructed components, by-products), moving from a property-based model to an 
access-based model, and developing a system of logistics and readmission services. All this requires a significant change in strategy and strategic decisions developed by the senior management team.

The company's strategy is related to the idea of building a competitive advantage, which puts the company in a better position than its competitors [8]. The basis of any competitive advantage is the ability of the company differentiate and thus create a unique proposition and provide more value to its customers compared to competitors. This implies a process of strategic planning and strategic decision-making for mission, vision, goals, scope of the organization and analysis of the external business environment, analysis, assessment of internal resources, competencies, investment planning, so that the development of the company allows maintaining a viable correspondence between goals, resources and competencies through change and adaptation.

In this process, the principles of circular corporate development must be incorporated implicitly, by including new practices in the overall set of business practices. There is no single set of circular practices, as each company has a unique business strategy, but there is a sufficient set of good practices that are applied taking into account the specifics of each company and the market in which it operates [9].

Circular development-oriented good practices include, in the first instance, a set of principles aimed primarily at analyzing the external environment and deepening relationships with stakeholders (customers, suppliers, owners, employees, financiers and regulators) and achieving higher level of approval, cooperation and satisfaction on their part. Good practices are a factor in creating distinctive features, a valuable, high-value strategic resource based on the analysis of the internal environment (technology, innovation, motivation, workforce incentives, history, reputation, financial resources and organizational structure). In other words, the application of the principles of the circular economy in the activity of the company requires a new strategic approach based on an indepth analysis of the influence of both external and internal resources/factors.

The analysis of the external and internal environment is a condition for the development of a new, circular model. Each business model directs and describes the way the company connects internal resources and distinctive competencies and their development with the opportunities to create, offer and realize additional value to its customers, which is a factor in building competitive advantages and achieving company goals [10]. In this sense, it is a conceptual framework that helps to link the company's strategy with the way it competes, with its activities and the implementation of the strategy. The company's strategy is one, although dynamic, but it can have different business models in order to achieve its goals. In order to ensure the realization of this main goal, each operating business model must be considered critically from a dynamic point of view, as internal and/or external changes in the environment require the development of the model or innovation in it.

The new business model must include the concept of circular development by building an integrated vertical management chain in which all participants create and impose higher standards and requirements for the final product, development of innovative and ecological thinking of clients and creating a company proposal that provides higher added value (environmental, social and economic). The building of a strategic competitive advantage (in the three dimensions) is measured by a sufficiently wide range of results, and not simply by the realized profit.

On this basis, the author develops a conceptual model "Model of strategic management - relationship between the circular development and the building of 
competitive company advantages" and defines the following hypotheses that must be tested empirically (Fig.3):

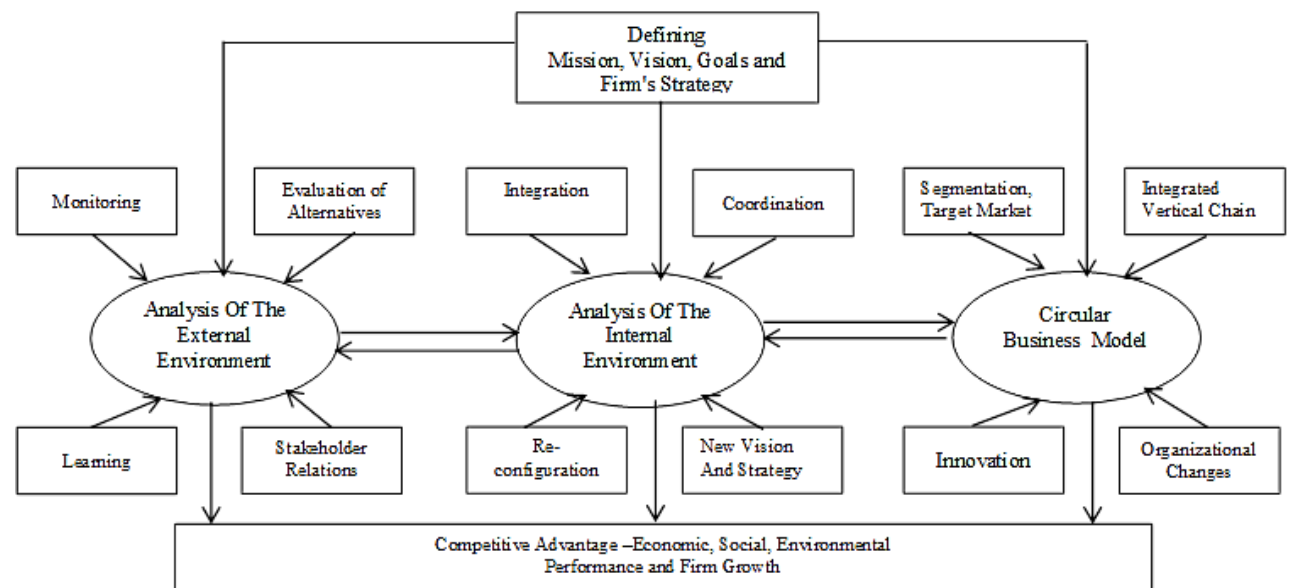

Fig. 3. Model of strategic management - relationship between the circular development and the building of competitive advantages

Hypothesis 1: The analysis of the external environment has a positive connection with the circular development and is a factor for building competitive company advantages (economic, environmental and social) and performance.

Hypothesis 2: The analysis of the internal environment has a positive connection with the circular development and is a factor for building competitive company advantages (economic, environmental and social) and performance.

Hypothesis 3: The analysis of a new business model has a positive connection with the circular development and is a factor for building competitive company advantages (economic, environmental and social) and performance.

Hypothesis 4: Evaluation of the realized competitive advantages (economic, ecological and social) and the performance - a function of the strategic management and the circular development of the company.

\section{EMPIRICAL STUDY OF THE THEORETICAL MODEL AND HYPOTHESES}

\subsection{Method and object of the research}

The empirical research was conducted using a developed and applied methodology for evaluating the defined hypotheses. The survey includes 26 randomly selected companies that have been operating for more than 5 years and have sufficient experience in a dynamic environment. The companies work on different segments of the construction market and have different specialization, different history, different territorial location, different business model, which allows to make generalizations with the necessary objectivity. An equal number of small, medium and large companies have been studied, which have different resources and competencies related to production, organization and management, have different market positioning and different opportunities to apply the principles of the circular economy. 


\section{sciendo}

40 Ovidius University Annals Series: Civil Engineering, Year 23, 2021

\subsection{Procedure and research tools}

The information was collected through an online survey among senior managers of selected companies. The specificity of the researched problem requires the inclusion of one respondent from each company, who, however, is assumed to have complete information and knowledge about the company he manages.Due to the expressed desire of most of them for confidentiality and anonymity (referring to company secrets), the respondents are given the opportunity to submit the survey without indicating the name or the name of their company. Of the questionnaires sent to 55 companies, 42 were returned, 16 of them were rejected due to lack of complete answers, which ultimately led to a sample of 26 companies and 26 managers.

The questionnaire included a total of 30 questions, constructed as wording, which the respondents referred to, noting their answers from 1 to 5 on the Likert scale (where 1 means "strongly disagree" and 5 means "strongly agree"). As the aim is to determine the correlation and assess the impact of strategic management on the circular development and building competitive advantages in the three dimensions (economic, social and environmental) and performance the issues are divided into four parts, which follow the formulated hypotheses. The questions are formulated in an understandable way, the necessary explanations for certain terms have been added, but this does not exclude the influence of the subjective factor in the evaluation of the achieved results, which is a result of the applied specific practices.

In order to determine the influence of the external environment on the circular development and the building of competitive company advantages (economic, ecological and social) in the survey special attention is paid to the following problems:

- Changes in tastes, preferences, consumer demand for environmentally friendly products.

- Behavior of competitors and possible reactions.

- Assessment of the legal framework, norms, standards in this direction, requirements and regulations.

- Processing of the collected information and evaluation of the alternatives for the company development.

- Capacity to acquire, assimilate and create new knowledge, skills, new way of thinking.

- Opportunities for more active communication with direct and indirect stakeholders.

- Discovering new combinations of resources and developing programs and plans to change and reconfigure existing operational competencies.

The assessment of the dynamics of the external environment includes activities that have common characteristics for all companies, but they are applied in a specific way, a function of the capacity and abilities of managers, which makes them relatively complex and difficult to reproduce.

The analysis of the internal environment includes activities related to development, change, reconfiguration of resources and competencies of the company, response to the dynamics of the external environment. The surveyed managers give their assessment on the following main issues:

- Creating a mechanism for integrating individual knowledge into a collective system that provides new configurations of resources and opportunities.

- Development of a new vision and development strategy that takes into account the interests of customers, company and society. 
- Coordination and building loyalty of all stakeholders, which allows the company to reevaluate the resource and find a way to use it in a new, more efficient way by exchanging information.

- Allocation of tasks, resources and synchronization of business activities, which changes functional competencies and creates new resources.

- Creating conditions for the implementation of strategic decisions and flexibility, adapting the company to the dynamics of the external environment.

Each business model is developed "from the outside - inside" and includes the following sequential steps, which are evaluated by the recipients:

- Effective market segmentation, selection of target market.

- Assessment of the possibilities for creating the desired product and the need for change.

- Reconfiguration, acquisition and integration of resources and capabilities.

- Creating an integrated vertical management chain and active inter-company knowledge transfer.

- Creating efficient circular deliveries in order to use recycled materials.

- Development of new technologies that allow recovery and use of useful resources from by-products or discarded products.

- Develop an effective marketing policy aimed at extending the life of the product and its components through repair, modernization, processing and resale, or developing models that increase the use of products through sharing, access to property.

- Management and organizational changes.

- Development of a system of incentives and motivation, conflict management and resolution.

The assessment of competitive advantages and performance is made according to some key indicators included in the GRI [11]:

- Direct economic impacts (Customers, Suppliers, Employees, Providers of Capital, Public Sector).

- Environmental (Materials, Energy, Water, Biodiversity, Emissions, effluents and waste, Products and services).

- Labour practices (Employment, Labour/management relations, Health and safety, Training and education, Diversity and opportunity).

- Human rights (Strategy and management, Freedom of association and collective bargaining, Child labour, Forced and compulsory labour, Disciplinary practices, Security practices).

- Society (Community, Bribery and corruption, Political contributions, Competition and pricing).

- Product Responsibility (Customer health and safety, Products and services, Advertising, Respect for privacy).

- Evaluation of company performance - financial indicators.

\section{RESULTS AND CONCLUSION}

When analyzing the results, the average values of the answers given by the online survey were first calculated. Thus, the influence of the individual components of the strategic management on the circular development and the building of competitive advantages is determined, which are also assessed by the indicated indicators. On this basis, the Pearson coefficient $(\mathrm{R})$ was calculated for the whole sample to establish the relationship 
between the analysis of the impact of the external, internal environment and the creation of a new business model on the circular development of the construction company and the construction of competitive advantages (Table 1). The correlation between the realization of competitive advantages (economic, environmental and social) and performance is also determined - a function of the creation of strategic management, oriented towards the application of the principles of the circular economy (Table 2).

The calculated Pearson correlation coefficient in Tables 1 and 2 is statistically significant, indicating that there is a relationship between the studied variables.

The obtained results prove the existence of a significant positive correlation between the analysis of the external, internal environment and the creation of a new business model with the circular development and the building of competitive company advantages (economic, environmental and social) and performance. Since the correlation coefficient is significantly greater than zero, this by definition allows the rejection of the null independence hypothesis.

Table. 1. Correlation analysis between the impact of external, internal environment and the creation of a new business model on the circular development of the construction company and build a competitive advantage

\begin{tabular}{|c|c|c|}
\hline $\begin{array}{c}\text { Strategic Management } \\
\text { Oriented Towards Circular } \\
\text { Development }\end{array}$ & & $\begin{array}{c}\text { Circular Development } \\
\text { Competitive Advantages } \\
\text { (Economic, Environmental } \\
\text { and Social) and } \\
\text { Performance }\end{array}$ \\
\hline $\begin{array}{c}\text { Analysis of the external } \\
\text { environment }\end{array}$ & $\begin{array}{c}\text { Pearson Correlation }-\mathrm{R} \\
\mathrm{N}=26\end{array}$ & 0.624 \\
\hline $\begin{array}{l}\text { Analysis of the internal } \\
\text { environment }\end{array}$ & $\begin{array}{c}\text { Pearson Correlation }-\mathrm{R} \\
\mathrm{N}=26\end{array}$ & 0.765 \\
\hline Circular business model & $\begin{array}{c}\text { Pearson Correlation }-\mathrm{R} \\
\mathrm{N}=26\end{array}$ & 0.835 \\
\hline
\end{tabular}

Correlation is significant at the 0.01 level (1-tailed). Source: Own calculations

Table 2. Correlation between the realization of competitive advantages (economic, environmental and social) and performance as a function of strategic management oriented towards circular development

\begin{tabular}{|c|c|c|}
\hline & & $\begin{array}{c}\text { Strategic Management } \\
\text { Oriented Towards Circular } \\
\text { Development }\end{array}$ \\
\hline $\begin{array}{c}\text { Competitive Advantages } \\
\text { and Performance }\end{array}$ & $\begin{array}{c}\text { Pearson Correlation - R } \\
\mathrm{N}=26\end{array}$ & 0.636 \\
\hline
\end{tabular}

Correlation is significant at the 0.01 level (1-tailed). Source: Own calculations

Respondents are unanimous that the application of the principles of circular development requires a significant change in strategic management - strategic behavior, strategic decisions and actions that allow the creation of a construction product that has a high consumer rating, provides a healthier life, better working atmosphere and reduces the negative impact on the environment, which in practice means building competitive company advantages.

This requires a new and mostly holistic approach in the organization of the company, which integrates a wide range of practices for design, construction, operation, maintenance, 
demolition, and the principles of circular corporate development are implicitly embedded through the development and implementation of new practices in the whole set of business practices. These include, first and foremost, company actions aimed at analyzing the external environment. Respondents understand the importance of the process of monitoring, assessing alternatives and threats, knowledge transfer and deepening relationships with stakeholders (customers, suppliers, owners, employees, financiers and regulators) as a factor in building competitive advantage (the first hypothesis $\mathrm{H} 1=0.624$ ), but also the complex problems facing them related to the legal framework, requirements and regulations, development of communication and building trust with direct and indirect stakeholders.

Respondents attach the greatest importance to the analysis of the internal environment for the realization of company goals (the second hypothesis - $\mathrm{H} 2=0.765$ ). It is a factor in creating distinctive features, a valuable, high-value strategic resource based on technology development, innovation, motivation, workforce incentives, history, reputation, financial resources and organizational structure. According to them, a radical change is needed in the strategic behavior, organization and management of the company through a process of integration and coordination of individual knowledge in a collective system that allows creating new configurations of resources and opportunities and developing a new vision and development strategy, which takes into account the interests of the three parties customers, company and society.

The study also confirms the third hypothesis $(\mathrm{H} 3=0.835)$ - the relatively strong correlation between the need to create a new circular business model as a factor for circular development and building competitive company advantages. Central is the creation of an integrated vertical chain that connects all participants not only physically through the product but also digitally, and allows active transfer of knowledge between partners, efficient circular deliveries to use recycled materials, of useful resources from discarded or by-products. The circular business model can also be aimed at extending the life of the product and its components, or using it through sharing, access to property, as well as building long-term relationships with customers, offering additional services, which increases the productivity of resources and the benefits of circular development.

Managers are adamant that the decentralized company structure, the ability to coordinate the different goals of different groups and the company as a whole, the creation of identity, culture, loyalty and reputation provide adaptation and coordination of internal resources and competencies to external changes, development of intangibles assets (learning, knowledge, innovation), which in turn have a reciprocal impact and develop tangible assets. The fourth hypothesis $(\mathrm{H} 4=0.636)$ proves that the strategic management and the circular development of the company can provide competitive advantages, assessed with specific indicators, including assessment of economic, environmental and social benefits.

The main limitation of the present study is the subjective nature of the responses. The presented model of strategic management as a link between circular development and the building of competitive company advantages is developed on the basis of known good practices. They have common characteristics, but should be applied specifically in different companies, because they differ in their history of experience, knowledge, routine, specialization, etc., i.e. they have different organizational characteristics, abilities and skills. In each specific company, managers should develop specific solutions and apply specific methods, approaches, analytical procedures and routine actions. Especially important for the company's success is the application of a unified, complex approach in the process of creating sustainable and circular practices that skillfully combine the development of internal and external factors/resources. 


\section{REFERENCES}

[1]. European Commission. (2015). Communication From The Commission to the European Parliament, the Council, the European Economic and Social Committee and the Committee of the Regions: Closing the Loop — an EU Action Plan for The Circular Economy, https://europa.eu/rapid/press-release_ip-15-6203_en.htm

[2]. A European Green Deal | European Commission, https://ec.europa.eu/info/strategy/priorities-2019-2024/european-green-deal)

[3]. European Commission. (2020). Communication from the commission to the european parliament, the council, the european economic and Social committee and the committee of the regions. A new circular economy Action plan. For a cleaner and more competitive europe. https://ec.europa.eu/environment/strategy/circular-economy-action-plan_en

[4]. Ellen Macarthur Foundation. (2012). Towards the Circular Economy: Economic Business Rationale For An Accelerated Transition.

[5]. Ivanova, V., Chipeva, S. (2021). The Impact of Green Thechnologies on Transition to Circular Economy. Management and Business Research Quarterly, 2021, Vol.17, pp. 5571, https://doi.org/10.32038/mbrq 2021.17.05

[6]. European Commission. (2014). Communication From The Commission To The European Parliament, The Council, The European Economic And Social Committee And The Committee Of The Regions: Towards A Circular Economy: A Zero Waste Programme For Europe.

http://eur-lex.europa.eu/legal-content/en/txt/?uri=celex:52014dc0398r\%2801\%29 (accessed 18 june 2016)

[7]. Preston, F. (2012). A Global Redesign? Shaping the Circular Economy. Chatham House - The Royal Institute of International Affairs Briefing paper.

[8]. Henderson, B. (1989).The Origin of Strategy. Harvard Business Reyiew, 67(6), pp.139143.

[9]. Goldsmith, S., Samson, D. (2005). Sustainable Development and Business Success. A Report Of The Australian Business Foundation And The Foundation For Sustainable Economic Development At The University Of Melbourne

[10]. Osterwalder, A., Pigneur, Y. (2010). Business Model Generation. Wiley \& Sons, Hoboken, Teece, D. (2010). Business models, business strategy and innovation. Long Range Planning, Vol. 43, Iss. 2-3, April-June, pp. 172-194

[11]. Global Reporting Initiative. (2002). Sustainability Reporting Guidelines, Boston, Mass: Global Reporting Initiative

\section{Note:}

Aneta Marichova - University of Architecture, Civil Engineering and Geodesy, 1, Hristo Smirnensky Boulevard, 1046-Sofia, Bulgaria (corresponding author to provide e-mail:aneta.marichova@abv.bg, marichova fte @uacg.bg) 